\title{
Exposure to Long-Term Air Pollution and Incidence of Peripheral Arterial Disease in the General Population: A National Population-Based Retrospective Cohort Study
}

\author{
Jun Gyo Gwon \\ Korea University College of Medicine, Anam Hospital \\ Ji Hun Park \\ Hanyang University Guri Hospital, Hanyang University \\ Joung Soo Kim \\ Hanyang University Guri Hospital, Hanyang University \\ Hyun-Min Seo ( $\sim$ blackshm@hanyang.ac.kr) \\ Hanyang University Guri Hospital, Hanyang University
}

\section{Research Article}

Keywords: air pollution, nitrogen dioxide, particulate matter, peripheral arterial disease, sulfur dioxide

Posted Date: May 13th, 2021

DOl: https://doi.org/10.21203/rs.3.rs-506193/v1

License: (c) (i) This work is licensed under a Creative Commons Attribution 4.0 International License.

Read Full License 


\section{Abstract \\ Objective}

This study aimed to evaluate the causal relationship between long-term outdoor air pollutants and incidence of peripheral arterial disease (PAD) using the National Health Insurance Service-National Sample Cohort (NHIS-NSC) database.

\section{Methods}

This study is retrospective study. We included 292,091 subjects from the general population who had previously not been diagnosed with PAD by the NHIS-NSC between 2008 and 2014. Hourly air pollutant data (particulate and gaseous) and climate data were collected. Correlation analysis of the collected data confirmed the relationship between air pollution and PAD incidence.

\section{Results}

For 1,836,965.4 person-years, incident cases of PAD were observed in 5,243 subjects $(285.4 / 100,000$ person-years). In the Cox proportional hazard analysis, there was a significant association between the incidence of PAD and long-term average concentration of $\mathrm{SO}_{2}$ (hazard ratio [HR], 1.686; 95\% confidence interval [Cl], 1.108-2.565) and $\mathrm{NO}_{2}(\mathrm{HR}, 1.200 ; 95 \% \mathrm{Cl}, 1.077-1.336)$ after the adjustment for variables.

\section{Conclusions}

This study demonstrated that $\mathrm{SO}_{2}$ and $\mathrm{NO}_{2}$ exposure are independent risk factors for PAD. On the other hand, new-onset PAD was not affected by exposure to particulate matter such as $\mathrm{PM}_{2.5}$ and $\mathrm{PM}_{10}$.

\section{Introduction}

Global emissions of $\mathrm{SO}_{2}$ and $\mathrm{NO}_{2}$ peaked and then declined in 2020 in Europe and North America as a result of widespread emission controls for sulfur and nitrogen oxides $\left(\mathrm{SO}_{\mathrm{x}}\right.$ and $\left.\mathrm{NO}_{\mathrm{x}}\right)$ (1). On the other hand, air pollution emissions in South and East Asia, where half of the world's population lives, continue to increase; the air quality in Asian countries is worse than those in other countries $(2,3)$. Some studies have shown that exposure to air pollution increases the incidence of and mortality associated with cardiovascular diseases (CVDs) (4-7). However, these studies analyzed arrhythmia, coronary arterial disease, or stroke among CVD patients, but only a few investigated peripheral arterial disease (PAD) $(4,8$, 9). PAD, a CVD, has the pathophysiology of atherosclerosis-related diseases; the risk factors of its onset and disease progression do not differ from those of other CVDs. However, the odds ratio of each risk factor for onset and progression vary depending on the CVD $(10,11)$. This may be because the function 
and location of the involved arteries differ among diseases. Therefore, it remains unclear whether the incidence of PAD is related to air pollution and whether there may be differences in the incidence of PAD depending on air pollutant type. This study aimed to evaluate the causal relationship between outdoor air pollutants by type and PAD incidence using data from the National Health Insurance Service-National Sample Cohort (NHIS-NSC) database.

\section{Results}

\section{Baseline and clinical characteristics of incident cases of PAD}

A total of 292,091 subjects not previously diagnosed with PAD were included in this study. For a total of $1,836,965.4$ person-years, we identified 5,243 incident cases of PAD (285.4/100,000 person-years). Among the patients with PAD, the mean age was $57.42 \pm 15.01$, and $53.57 \%$ were female. The most prevalent comorbid diseases were hypertension (54.93\%), followed by diabetes mellitus $(27.71 \%)$ and dyslipidemia (26.82\%). The demographic and clinical characteristics of the study population are summarized in Table 1.

\section{Association between air pollution and incidence of PAD}

The Cox proportional hazard analysis revealed a significant association between the incidence of PAD and long-term average concentrations of $\mathrm{SO}_{2}$ and $\mathrm{NO}_{2}$ (Table 2). After the adjustment for age and sex (model 1) and age, sex, and economic status (model 2), $\mathrm{SO}_{2}$ and $\mathrm{NO}_{2}$ exposure showed a significantly increased risk for PAD, respectively. On the other hand, the association between $\mathrm{O}_{3}, \mathrm{CO}, \mathrm{PM}_{10}$, and $\mathrm{PM}_{2.5}$ exposure and the incidence of PAD was not significant. We fit a Cox proportional hazards model that included spline terms for continuous covariates of other pollutants and climate variables, and a significant relationship was observed between the $\mathrm{SO}_{2}$ and $\mathrm{NO}_{2}$ long-term average concentration and incidence of PAD at observed values above 0.005187 ppm and 0.03404 ppm, respectively (Fig. 1).

In subgroup analyses to evaluate the association between covariates and risk of PAD, as age increased (HR, 1.065; 95\% Cl, 1.063-1.066 per year) and the proportion of female sex increased (HR, 1.386; $95 \% \mathrm{Cl}$, $1.312-1.465)$, the risk of PAD significantly increased. Among the comorbid diseases, hypertension (HR, 6.139; 95\% Cl, 5.814-6.483), diabetes mellitus ( $\mathrm{HR}, 4.612 ; 95 \% \mathrm{Cl}, 4.341-4.900)$, dyslipidemia (HR, 4.533; $95 \% \mathrm{Cl}, 4.264-4.819)$, angina pectoris ( $\mathrm{HR}, 4.840 ; 95 \% \mathrm{Cl}, 4.454-5.258)$, myocardial infarction ( $\mathrm{HR}, 3.906$; $95 \% \mathrm{Cl}, 3.119-4.892)$, stroke (HR, 6.125; $95 \% \mathrm{Cl}, 5.619-6.677)$, and congestive heart failure (HR, 3.711; $95 \% \mathrm{Cl}, 1.855-7.424)$ all significantly increased the risk of PAD (Table 3 ).

\section{Discussion}

We conducted a retrospective cohort study of 292,091 subjects to investigate the causal relationship between air pollutant exposure and the incidence of PAD. The results of the analysis demonstrated 
several important findings. First, exposure to $\mathrm{SO}_{2}$ and $\mathrm{NO}_{2}$ was significantly associated with an increased risk of PAD in the general population. Second, particulate matters such as $\mathrm{PM}_{2.5}$, and $\mathrm{PM}_{10}$ were not significantly associated with the incidence of PAD.

The first mechanism is a thrombogenic effect caused by platelet activation. Animal study results showed that fossil fuel exhaust particulates are directly translocated into the blood circulation through alveolar capillary trigger platelet activation and cause arterial thrombosis (12). This mechanism resulted in the same results in humans. The experimental subjects composed of volunteers who had developed thrombosis with rapid platelet aggregation (13). Thrombosis due to platelet activation induces CVDs including PAD. The second mechanism is inflammation. Inflammation is a risk factor for PAD. When exposed to fossil fuel exhaust air pollutants such as $\mathrm{SO}_{2}$ or $\mathrm{NO}_{2}$, the inhaled air particulates directly stimulate the macrophages or alveolar epithelium inside the lungs, causing inflammation. Inflammation occurs when cells stimulated by $\mathrm{SO}_{2}$ or $\mathrm{NO}_{2}$ produce reactive oxygen species (ROS), resulting in oxidative stress (14). Oxidative stress activates transcription factors such as nuclear factor-kappaB, which express pro-inflammatory mediators, cytokines, and chemokines (15). Inflammation is indirectly induced by fossil fuel exhaust particulates aggravating the disease in patients with chronic respiratory diseases such as asthma, COPD, and interstitial lung disease, which causes generalized inflammation. The third mechanism is the induction of hypertension, a well-known risk factor for CVD. Inhaled air pollution can downregulate nitric oxide synthase and affect autonomic nervous system dysfunction (16). These events result in vasoconstriction and hypertension, which persist for up to 1 day (17). In addition, the incidence of PAD is increased by mechanisms such as atherosclerosis or atherosclerotic plaque instability inducing plaque rupture (18).

Previous studies confirming the correlation between the existing CVD incidence and air pollution revealed that PM causes coronary artery disease (CAD), but there was no correlation in the incidence of PAD (19, 20). PAD and $C A D$ showed different results depending on air pollution type, and among the mechanisms that affect the cardiovascular system, those that directly affect the heart are important. These mechanisms were applied only to CAD incidence and not PAD incidence among the PM exposure effects. The first mechanism is that PM directly affects cardiomyocytes. Exposure of the alveolar epithelium to PM increases ROS production (14). Excessive increases in ROS cause cardiomyocyte cell damage (21). $\mathrm{PM}$-induced peroxide production affects calcium regulation in the $\mathrm{Na}-\mathrm{Ca}$ exchange channel (22). This increases the concentration of cytosolic calcium and reduces cardiac contractility, leading to cardiac hypertrophy. Second, PM influences autonomic nervous system regulation, causing heart rate variability, which induces arrhythmia $(23,24)$. The activation of the sympathetic drive increases the incidence of cardiac arrhythmia and the risk of cardiovascular morbidity, including cardiac muscle remodeling and heart failure.

The main advantage of this study is that it analyzed real-world data. Its follow-up period was long. Previous CVD-related studies limited the period of air pollution exposure, so there is a limit to confirming how it affects daily life, but this study included a follow-up period of more than 4 years. Second, existing studies were conducted in places where the concentrations of air pollution were relatively low. Cities in 
Europe and North America may have underestimated the impact of air pollution on CVD, as their air pollution levels were not as high as those in Asian metropolitan cities (1). However, this study was conducted in cities where the degree of air pollution was much higher than those previously studied. Third, we adjusted the socioeconomic status (SES) data during the analysis process. SES is an important variable because it affects the risk factors for PAD, and there may be differences in the use of air purification facilities, such as indoor air cleaners, depending on SES (25).

This study also has some limitations. First, for a more practical analysis, outdoor and indoor air pollution analyses should be performed simultaneously. Indoor and outdoor air pollution have different types or concentrations of particulates, and people are exposed to indoor air pollution as long as outdoor air pollution. Second, among the risk factors for PAD, smoking history is an important confounding factor, but there were no related data. Race is also a risk factor for PAD, but the results of this study are limited to Asian populations.

\section{Conclusions}

In the general population, long-term exposure to $\mathrm{SO}_{2}$ and $\mathrm{NO}_{2}$ is associated with an increased incidence of PAD. However, new-onset PAD was not affected by particulate matter exposure such as $\mathrm{PM}_{2.5}$ and $\mathrm{PM}_{10}$.

\section{Materials And Methods}

\section{Study design and database}

This retrospective cohort study examined approximately 1 million representative samples from the NHISNSC. One hundred percent of the Korean population is covered by the NHIS, which is divided into three categories: the National Health Insurance $(\mathrm{NHI})$ program for employees, the $\mathrm{NHI}$ for self-employed groups, and the medical aid system. In $2013,97.2 \%(n=49,989,620)$ of the population was covered by the $\mathrm{NHI}$, while the remaining $2.8 \%(n=1,458,871)$ of the population was covered by the medical aid system. Due to the large volume and lack of confidentiality regarding personal information in the $\mathrm{NHI}$ database, the NHIS-NSC was constructed as a representative sample database and contains a large volume of representative information that does not require privacy regulation. Subjects who were treated for PAD or comorbid diseases during the screening period (2002-2007) were excluded. For this study, information from January 2008 to December 2014 in the NHIS-NSC database was utilized. The subjects' age, sex, location, economic status, and diagnostic codes based on the International Classification of Diseases, Tenth Revision (ICD-10) were retrieved. This study was approved by the Ethics Committee of Hanyang University Guri Hospital (GURI 2020-02-010). The obligation for written informed consent was waived by the institutional review board (IRB) of the Ethics Committee of Hanyang University Guri Hospital. All analyses followed the instructions and guidelines of the IRB. All methods were carried out in accordance with relevant guidelines and regulations. This study was conducted in accordance with the principles of the Declaration of Helsinki. 


\section{Study subjects and definition of clinical outcomes}

Patients with ICD-10 codes $170.0,170.2$, 170.8, 170.9, 173.9, 174.0, 174, 174.1-5, 174.8, and I74.9 (PAD) were identified from the NHIS-NSC. Patients with comorbid diseases were defined as those with hypertension (ICD-10 codes I10-13 and I15), diabetes mellitus (ICD-10 codes E11-14), dyslipidemia (ICD-10 code E78), angina pectoris (ICD-10 code I20), myocardial infarction (ICD-10 codes I21 and I22), cerebral infarction (ICD-10 code I63), or congestive heart failure (ICD-10 codes I50). To improve the accuracy of the analysis, only subjects for whom there were at least two principal diagnostic codes for each disease were included. The date of disease diagnosis was used as the entry date for patients with disease.

\section{Measurements of air pollutants}

Ambient particulate matter $\left(\mathrm{PM}_{2.5}, \mathrm{PM}_{10}\right)$, gaseous air pollutants $\left(\mathrm{SO}_{2}, \mathrm{NO}_{2}, \mathrm{CO}\right.$, and $\left.\mathrm{O}_{3}\right)$, temperature, and humidity were measured hourly at the Korean Nationwide Meteorological Observatory site by the Korean Department of Environmental Protection. To assess the effects of long-term exposure to air pollution, the nearest monitor of each residence was identified and used to assess the average pollutant concentrations in each study subject. The geographically based average concentration of each air pollutant was measured hourly at the 313 monitoring facilities, and 256 residential ZIP codes were matched with the nearest monitoring facilities. Subjects for whom values were missing were excluded from the study. Since a nationwide measurement of fine particulate matter in Korea was not conducted before 2015, limited data measured in only some areas were utilized during the study period.

\section{Statistical analyses}

Incident cases of PAD were calculated by dividing the number of events by person-years at risk, while the incidence was compared based on the Cox proportional hazards model adjusted for exposure to other pollutants and meteorological variables (temperature and humidity). We performed subgroup analyses in terms of age, sex, economic status, and comorbidities. Differences were considered statistically significant when the $P$ value was less than 0.05. Data were analyzed using SAS Enterprise Guide 7.13 (SAS Institute, Cary, NC, USA), and the graphs were visualized with RStudio (version 1.0.136; R Project for Statistical Computing).

\section{Declarations}

\section{Author contributions}

J. G. G., H. M. S. and J. S. K. planned the experiments, J. G. G. and H. M. S. preformed the data analysis. All authors edited the manuscript.

\section{Funding sources:}

This work was supported by the research fund of Hanyang University (HY-2020). 
The authors declare no conflicts of interest.

\section{References}

1. Fowler, D. et al. A chronology of global air quality. Philos T R Soc A. 378, 2183 (2020).

2. Wu, L. et al. A gridded emission inventory of semi-volatile and intermediate volatility organic compounds in China. Sci Total Environ. 761, 143295 (2021).

3. Purohit, P. et al. Mitigation pathways towards national ambient air quality standards in India.Environ Int. 2019;133.

4. Kaufman, J. D. et al. Prospective study of particulate air pollution exposures, subclinical atherosclerosis, and clinical cardiovascular disease: The Multi-Ethnic Study of Atherosclerosis and Air Pollution (MESA Air). Am J Epidemiol. 176 (9), 825-837 (2012).

5. Newby, D. E. et al. Expert position paper on air pollution and cardiovascular disease. Eur Heart J. 36 (2), 83-93 (2015).

6. Cramer, J. et al. Long-Term Exposure to Air Pollution and Incidence of Myocardial Infarction: A Danish Nurse Cohort Study. Environ Health Perspect. 128 (5), 57003 (2020).

7. Liu, Z. G. et al. Does utilizing WHO's interim targets further reduce the risk - meta-analysis on ambient particulate matter pollution and mortality of cardiovascular diseases? Environ Pollut. 242, 12991307 (2018).

8. Peng, R. D. et al. Acute effects of ambient ozone on mortality in Europe and North America: results from the APHENA study. Air Qual Atmos Health. 6 (2), 445-453 (2013).

9. Niu, Z. et al. Acute effect of ambient fine particulate matter on heart rate variability: an updated systematic review and meta-analysis of panel studies. Environ Health Prev Med. 25 (1), 77 (2020).

10. Rein, P. et al. Systemic inflammation is higher in peripheral artery disease than in stable coronary artery disease. Atherosclerosis. 239 (2), 299-303 (2015).

11. Jang, S. Y., Ju, E. Y., Cho, S. I., Lee, S. W. \& Kim, D. K. Comparison of Cardiovascular Risk Factors for Peripheral Artery Disease and Coronary Artery Disease in the Korean Population. Korean Circ J. 43 (5), 316-328 (2013).

12. Nemmar, A. et al. Diesel exhaust particles in lung acutely enhance experimental peripheral thrombosis. Circulation. 107 (8), 1202-1208 (2003).

13. Lucking, A. J. et al. Diesel exhaust inhalation increases thrombus formation in man. Eur Heart J. 29 (24), 3043-3051 (2008).

14. Mills, N. L. et al. Adverse cardiovascular effects of air pollution. Nat Clin Pract Cardiovasc Med. 6 (1), 36-44 (2009).

15. Shukla, A. et al. Inhaled particulate matter causes expression of nuclear factor (NF)-kappaB-related genes and oxidant-dependent NF-kappaB activation in vitro. Am J Respir Cell Mol Biol. 23 (2), 182187 (2000). 
16. Mills, N. L. et al. Diesel exhaust inhalation causes vascular dysfunction and impaired endogenous fibrinolysis. Circulation. 112 (25), 3930-3936 (2005).

17. Tornqvist, $\mathrm{H}$. et al. Persistent endothelial dysfunction in humans after diesel exhaust inhalation. $A m$ J Respir Crit Care Med. 176 (4), 395-400 (2007).

18. Fiordelisi, A. et al. The mechanisms of air pollution and particulate matter in cardiovascular diseases. Heart Fail Rev. 22 (3), 337-347 (2017).

19. Hoffmann, B. et al. Residential exposure to urban air pollution, ankle-brachial index, and peripheral arterial disease. Epidemiology. 20 (2), 280-288 (2009).

20. Diez Roux, A. V. et al. Long-term exposure to ambient particulate matter and prevalence of subclinical atherosclerosis in the Multi-Ethnic Study of Atherosclerosis. Am J Epidemiol. 167 (6), 667-675 (2008).

21. He, F. \& Zuo, L. Redox Roles of Reactive Oxygen Species in Cardiovascular Diseases. Int J Mo/ Sci. 16 (11), 27770-27780 (2015).

22. Coetzee, W. A., Ichikawa, H. \& Hearse, D. J. Oxidant stress inhibits Na-Ca-exchange current in cardiac myocytes: mediation by sulfhydryl groups? Am J Physiol. 266 (3 Pt 2), H909-19 (1994).

23. Brook, R. D. et al. Air pollution and cardiovascular disease: a statement for healthcare professionals from the Expert Panel on Population and Prevention Science of the American Heart Association. Circulation. 109 (21), 2655-2671 (2004).

24. Adar, S. D. et al. Focused exposures to airborne traffic particles and heart rate variability in the elderly. Epidemiology. 18 (1), 95-103 (2007).

25. Criqui, M. H. \& Aboyans, V. Epidemiology of peripheral artery disease. Circ Res. 116 (9), 1509-1526 (2015).

\section{Tables}


Table 1

Demographics and comorbidities of incident cases of peripheral arterial disease $(1,836,965.4$ personyears)

\begin{tabular}{|c|c|c|c|}
\hline Variable & $\begin{array}{l}\text { Incident cases of peripheral } \\
\text { arterial disease } \\
(n=5,243)\end{array}$ & $\begin{array}{l}\text { Subjects without peripheral } \\
\text { arterial disease } \\
(n=286,848)\end{array}$ & $\mathbf{P}$ \\
\hline Age (years; mean $\pm S D$ ) & $57.42 \pm 15.01$ & $33.76 \pm 19.89$ & $<.0001$ \\
\hline Female sex, n (\%) & $3,116(59.43)$ & $143,876(50.16)$ & $\dot{0} 0001$ \\
\hline $\begin{array}{l}\text { Socioeconomic status, } \mathrm{n} \\
(\%)\end{array}$ & & & $<.0001$ \\
\hline $0-20 \%$ & 789 (15.95) & $37,550(13.45)$ & \\
\hline $20-80 \%$ & $690(13.95)$ & $43,370(15.53)$ & \\
\hline $40-60 \%$ & $737(14.89)$ & $52,453(18.78)$ & \\
\hline $60-80 \%$ & $1,025(20.72)$ & $62,240(22.29)$ & \\
\hline $80-100 \%$ & $1,707(34.50)$ & $83,636(29.95)$ & \\
\hline \multicolumn{4}{|l|}{$\begin{array}{l}\text { Comorbid conditions, } \mathrm{n} \\
(\%)\end{array}$} \\
\hline Hypertension & $2,880(54.93)$ & $44,670(15.57)$ & $<.0001$ \\
\hline Diabetes mellitus & $1,453(27.71)$ & $20,602(7.18)$ & $<.0001$ \\
\hline Dyslipidemia & $1,406(26.82)$ & $19,487(6.79)$ & $<.0001$ \\
\hline Angina pectoris & $635(12.11)$ & $7,297(2.54)$ & $<.0001$ \\
\hline Myocardial infarction & $77(1.47)$ & $1,058(0.37)$ & $<.0001$ \\
\hline Stroke & $580(9.46)$ & $5,552(1.94)$ & $<.0001$ \\
\hline Congestive heart failure & $8(0.15)$ & $129(0.04)$ & 0.0004 \\
\hline $\begin{array}{l}\text { Follow-up duration } \\
\text { (months; mean } \pm \text { SD) }\end{array}$ & $39.86 \pm 25.00$ & $76.12 \pm 15.64$ & $<.0001$ \\
\hline SD, standard deviation & & & \\
\hline
\end{tabular}


Table 2

Ambient gaseous and particulate air pollution and incidence of peripheral arterial disease in the overall general population $(\mathrm{N}=292,091)$

\begin{tabular}{|c|c|c|c|c|c|c|}
\hline $\begin{array}{l}\text { Air } \\
\text { pollutant }\end{array}$ & $\begin{array}{l}\text { Crude } \\
\text { HR }(95 \% \mathrm{Cl})\end{array}$ & $\begin{array}{l}P \\
\text { value }\end{array}$ & $\begin{array}{l}\text { Adjusted (model } \\
1)^{*} \\
\text { HR }(95 \% \mathrm{Cl})\end{array}$ & $\begin{array}{l}P \\
\text { value }\end{array}$ & $\begin{array}{l}\text { Adjusted (model } \\
2)^{\star \star} \\
\text { HR }(95 \% \mathrm{Cl})\end{array}$ & $\begin{array}{l}P \\
\text { value }\end{array}$ \\
\hline $\mathrm{SO}_{2}^{\dagger}$ & $\begin{array}{l}1.610(1.077- \\
2.408)\end{array}$ & 0.0203 & $\begin{array}{l}1.710(1.125- \\
2.601)\end{array}$ & 0.0068 & $\begin{array}{l}1.686 \\
2.565)\end{array}$ & 0.0147 \\
\hline $\mathrm{NO}_{2}^{+}$ & $\begin{array}{l}1.139(1.025- \\
1.264)\end{array}$ & 0.0152 & $\begin{array}{l}1.196(1.074- \\
1.332)\end{array}$ & 0.0020 & $\begin{array}{l}1.200(1.077- \\
1.336)\end{array}$ & 0.0009 \\
\hline $\mathrm{O}_{3}^{+}$ & $\begin{array}{l}1.099(0.904- \\
1.337)\end{array}$ & 0.3418 & N/A & $\mathrm{N} / \mathrm{A}$ & $\mathrm{N} / \mathrm{A}$ & N/A \\
\hline $\mathrm{CO}^{\ddagger}$ & $\begin{array}{l}1.013(0.966- \\
1.062)\end{array}$ & 0.5958 & N/A & $\mathrm{N} / \mathrm{A}$ & $\mathrm{N} / \mathrm{A}$ & N/A \\
\hline $\mathrm{PM}_{10} "$ & $\begin{array}{l}1.006(0.990- \\
1.022)\end{array}$ & 0.4541 & N/A & $\mathrm{N} / \mathrm{A}$ & $\mathrm{N} / \mathrm{A}$ & N/A \\
\hline $\mathrm{PM}_{2.5}$ & $\begin{array}{l}1.022(0.994- \\
1.050)\end{array}$ & 0.1291 & N/A & $\mathrm{N} / \mathrm{A}$ & $\mathrm{N} / \mathrm{A}$ & N/A \\
\hline \multicolumn{7}{|c|}{$\begin{array}{l}\mathrm{Cl} \text {, confidence interval; } \mathrm{CO} \text {, carbon monoxide; } \mathrm{HR} \text {, hazard ratio; } \mathrm{NO}_{2} \text {, nitrogen dioxide; } \mathrm{O}_{3} \text {, ozone; } \mathrm{PM}_{2.5} \text {, } \\
\text { particulate matter }<2.5 \mu \mathrm{m} \text { in diameter; } \mathrm{PM}_{10} \text {, particulate matter }<10 \mu \mathrm{m} \text { in diameter; } \mathrm{ppb} \text {, parts per } \\
\text { billion; ppm, parts per million; } \mathrm{SO}_{2} \text {, sulfur dioxide }\end{array}$} \\
\hline \multicolumn{7}{|c|}{ *Adjusted for age and sex. } \\
\hline \multicolumn{7}{|c|}{${ }^{\star \star}$ Adjusted for age, sex, and economic status } \\
\hline \multicolumn{7}{|c|}{${ }^{\dagger}$ by $0.01 \mathrm{ppm}$ increase } \\
\hline \multicolumn{7}{|c|}{ fby $0.1 \mathrm{ppm}$ increase } \\
\hline "by $1 \mu \mathrm{g} / \mathrm{m}$ & crease & & & & & \\
\hline
\end{tabular}


Table 3

Associations between covariates and risks of peripheral arterial disease

\begin{tabular}{|lll|}
\hline Variable & HR $(95 \% \mathrm{Cl})$ & $\mathbf{P}$ \\
\hline Age, per year & $1.065(1.063-1.066)$ & $<0.0001$ \\
\hline Female sex & $1.386(1.312-1.465)$ & $<0.0001$ \\
\hline Socioeconomic status & & \\
\hline $0-20 \%$ & Reference & - \\
\hline $20-80 \%$ & $0.763(0.689-0.845)$ & $<0.0001$ \\
\hline $40-60 \%$ & $0.680(0.615-0.752)$ & $<0.0001$ \\
\hline $60-80 \%$ & $0.794(0.724-0.871)$ & $<0.0001$ \\
\hline $80-100 \%$ & $0.968(0.890-1.053)$ & 0.4478 \\
\hline Comorbid conditions & & \\
\hline Hypertension & $6.139(5.814-6.483)$ & $<0.0001$ \\
\hline Diabetes mellitus & $4.612(4.341-4.900)$ & $<0.0001$ \\
\hline Dyslipidemia & $4.533(4.264-4.819)$ & $<0.0001$ \\
\hline Angina pectoris & $4.840(4.454-5.258)$ & $<0.0001$ \\
\hline Myocardial infarction & $3.906(3.119-4.892)$ & $<0.0001$ \\
\hline Stroke & $6.125(5.619-6.677)$ & $<0.0001$ \\
\hline Congestive heart failure & $3.711(1.855-7.424)$ & 0.0002 \\
\hline Cl, confidence interval; HR, hazard ratio & \\
\hline & & \\
\hline
\end{tabular}


A Hazard ratio for incident cases of peripheral arterial disease

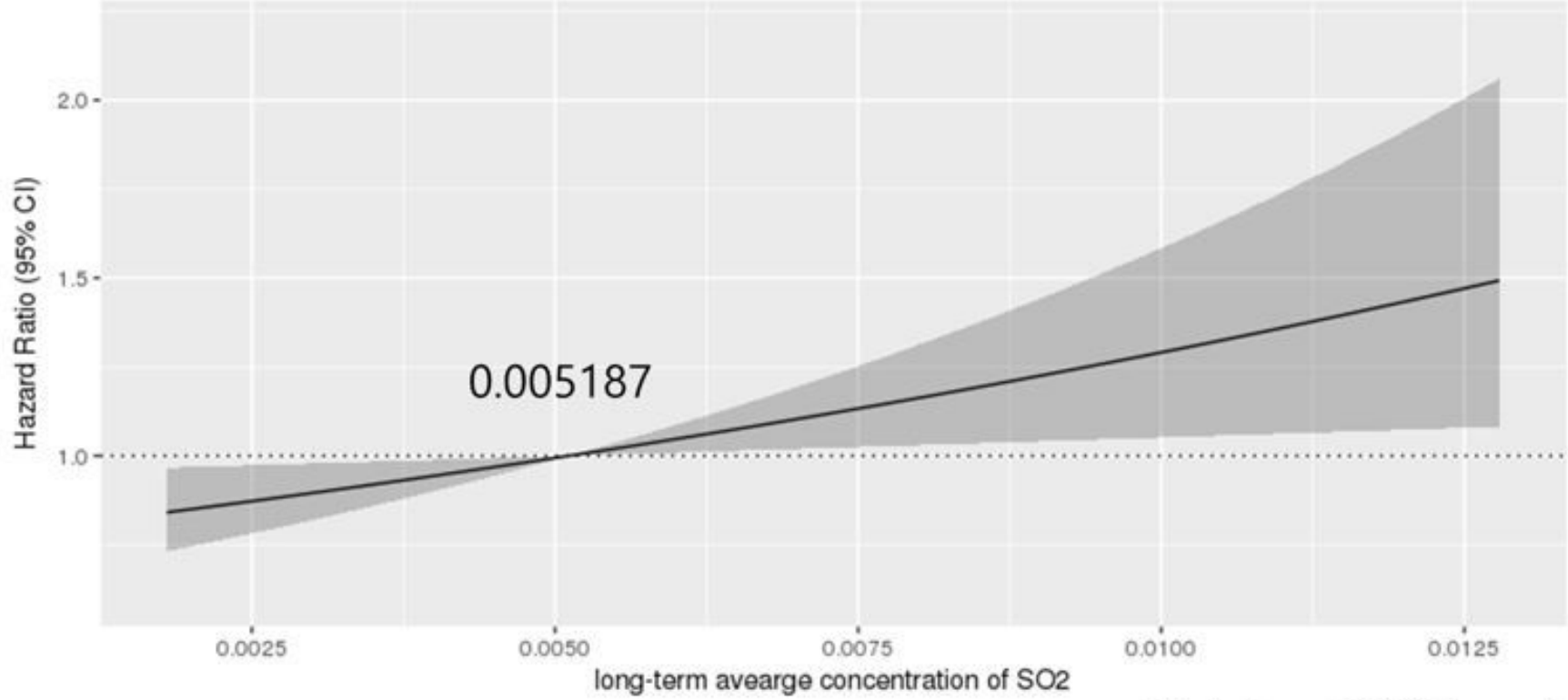

Adjusted to:age $=37$ SEX $=2$ income $=3$

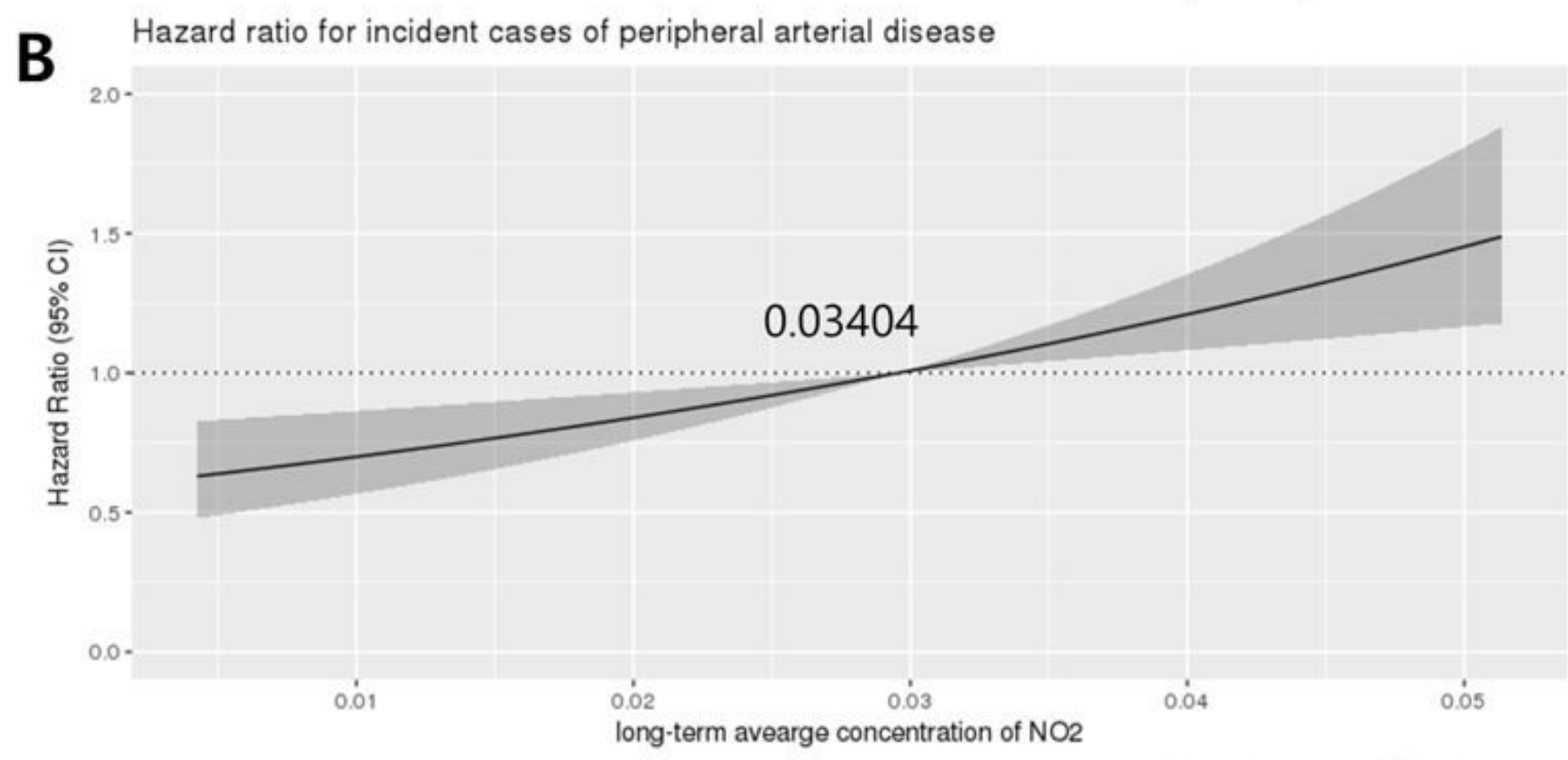

Acjusted to:age $=37 \mathrm{SEX}=2$ income $=3$

\section{Figure 1}

Concentration-response relationships of long-term exposure of SO2 (A) and NO2 (B) and incidence of peripheral arterial disease. The hazard ratio was adjusted for age, sex, and socioeconomic status $\mathrm{Cl}$, confidence interval 